\title{
TRAVEL TIME ANALYSIS OF SELECTED URBAN STREETS IN BAGHDAD CITY
}

\author{
${ }^{*}$ Rania M. Ahmed ${ }^{1}$
}

Zainab A. Alkaissi ${ }^{1}$
Ruba Y. Hussain ${ }^{1}$

1) Highway and Transportation Engineering Department, College of Engineering, Mustansiriyah University, Baghdad, Iraq

\begin{abstract}
Estimating travel time and measuring speed are critical for increasing the efficiency and safety of traffic road networks. This study presents an investigation of arterial travel time estimation for vital routes in Baghdad city. These estimations including speeds, stops, and delays were computed via GPS device and compared to those currently used to quantify congestion and travel time reliability. The study involved a 45-day survey of private vehicles in Baghdad utilizing a Global Positioning System (GPS) probe to collect data on traffic performance metrics for analysis in a GIS context. It was found that the proposed travel time performance measures show definite differences in estimates of peak-hour travel time as compared with weekend travel time. Route (1) from Bayaa intersection - Bab Al-Mutham intersection (through highway) produced a travel time of 165 minutes and 136 minutes for Bayaa intersection - Bab Al-Mutham intersection (through downtown). The travel speed of routes 1 and 2 are observed near $25 \mathrm{kmph}$ which is below the local speed limit of $70 \mathrm{kmph}$. The maximum travel time of routes 1 and 2 are 71 minutes and 37 minutes, respectively. While delay time was observed 45 and 20 minutes due to traffic congestion on route 1 and 2, respectively. The majority of vehicles are capable of traveling at normal speeds, with relatively few exceeding them.
\end{abstract}

Keywords: Travel time, Speed, Delay, GPS, Traffic Congestion.

\section{Introduction}

The travel time of an urban arterial in a city is cr ucial when evaluating the performance of a traff ic transportation system [1,2]. Congestion occurs when a highway becomes congested due to the presence of an excessive number of vehicles at one time, resulting in slower speeds than normal or "free flow" speeds $[3,4]$. When traffic is congested, a long line forms on the road, causing vehicles to start and halt as the route's planned capacity is exceeded. As a result, cars attempting to use the route experience delays, and travelers are unable to make their scheduled departures $[5,6]$.

Hunter et al. (2006) described a feasible technique for collecting and evaluating trip time data using GPS that accurately reflects performance indicators for segments as well as long arterial sections. This strategy is predicated on the idea that both average travel speed and average junction approach delay can be estimated as functions of arterial segment travel time, with travel time serving as the primary field measurement for evaluating arterial performance. Field data collection techniques based on GPS technology were developed, as well as algorithms for analyzing the GPS-based trip time data collected [7].

Mazloumi et al. (2010) explored day-to-day variations in public transportation travel times in

*Corresponding Author: edma013@uomustansiriyah.edu.iq 
Melbourne, Australia, by collecting GPS data for a bus route. According to the data, travel time distributions are better represented by normal distributions in smaller departure time frames. For longer departure time windows, peak-hour travel times follow normal distributions, but offpeak travel times follow lognormal distributions. Land use, route length, the number of traffic signals, the number of bus stops, and departure delay relative to the desired departure time all contribute to the variability of travel times. The AM peak has a greater degree of travel time variability than the off-peak. Only during the AM peak does rainfall have a significant effect on travel time variances [8].

Al-Kaissi (2017) provided a detailed travel time calculation and distribution analysis for three routes along Baghdad's Palestine Arterial Street: Bab Al Mutham junction to Al-Sakara intersection, Al-Mawall intersection to Bab Al Mutham intersection, and Al-Sakara Intersection to Beirut Intersection. Dependability is harmed by the buffer time index. Different predicted models for the three analyzed Palestine street routes have been created using field data [1].

Hasan and Hossain (2019) The degree of traffic congestion in Pabna town was determined, as well as the location of the congestion within the town. The study's principal methodological tools were spot speed testing and trip and delay studies. The data was analyzed with the use of a range of statistical software applications. According to the research, Pabna town's average speed is 13.67 kilometers per hour, with average journey times of 3.38 minutes or 203 seconds. According to the research, one-way traffic flow and strict enforcement of traffic restrictions are possible solutions to the town's traffic congestion [9].

\section{Objective of the Research}

The goal of this study is to calculate total travel time and conduct a speed distribution analysis on two selected routes in Baghdad, which are considered to be the city's most important residential and commercial areas due to the drastic changes that may impact daily trip generation and attraction.

\section{Study Area}

In this study, two routes have been selected in Baghdad city which meet all the characteristics of traffic condition, arterial roads and collectors' roads [10]. Bayaa intersection - Bab Al-Mutham intersection (highway route) and Bayaa intersection - Bab Al-Mutham intersection (downtown route). These Routes are heavily urbanized and commercialized containing many restaurants and shopping venues. Numerous unsignalized access points exist along the facility ranging from private driveways to large Mall entrances. All the selected routes are shown in Fig. 1.

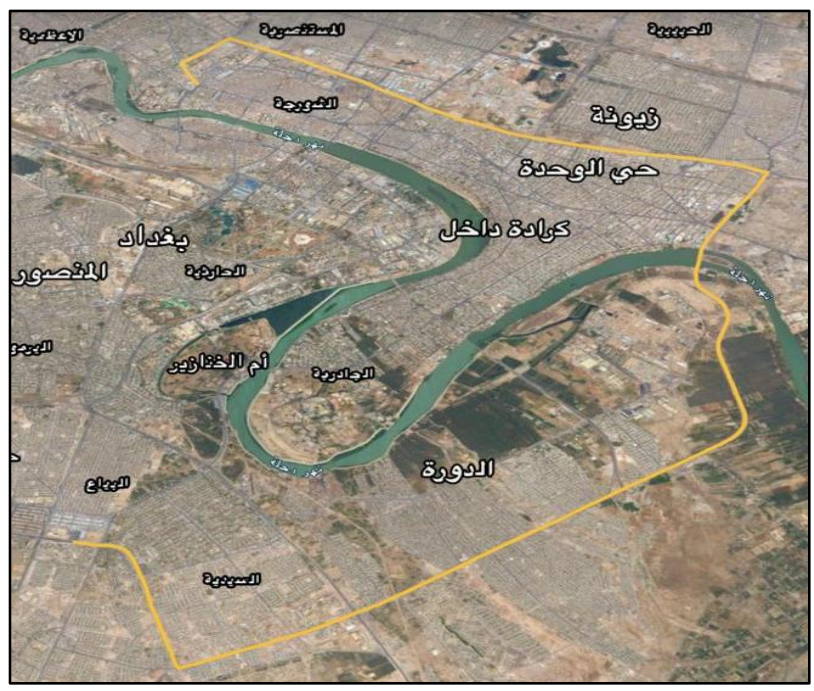

a) Bab Al-Mutham intersection (Route 1) 


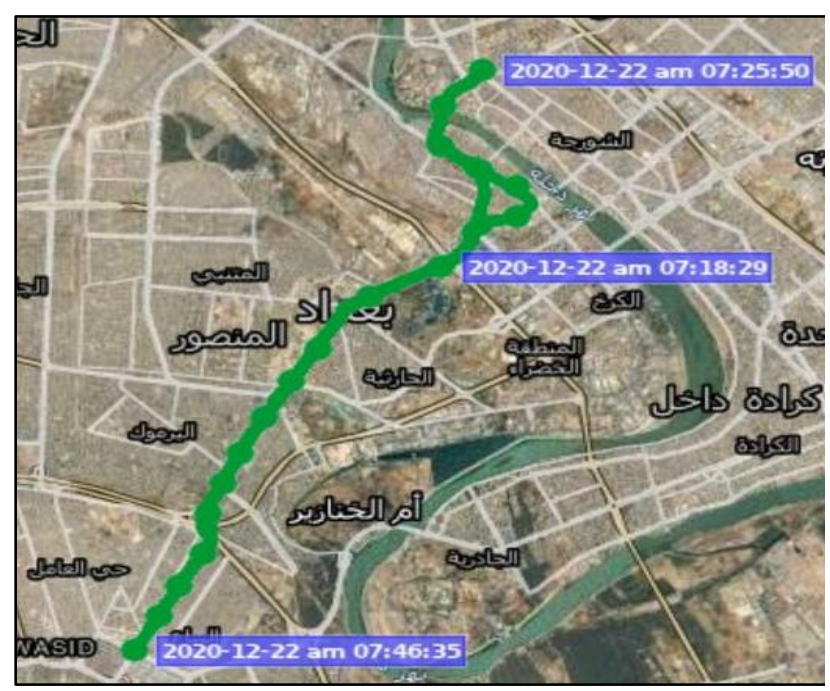

b) Bayaa intersection - Bab Al-Mutham intersection (Route 2)

Figure 1. Overall map of the study routes

\section{Data Collection Method}

Travel time and speed data are required for evaluating various travel time reliability and congestion indices. WENK GPS device is utilized to extract trip time and speed data for the routes in this investigation. WENK GPS is an Iraqi business based in Erbil. From January $1^{\text {st }}$ to February $28^{\text {th }}, 2021$, this software collects data from highway detectors and estimates extra traffic observed between (7-9 AM) and (1-3 $\mathrm{PM})$. The WENK GPS interface is shown in Figure 2.

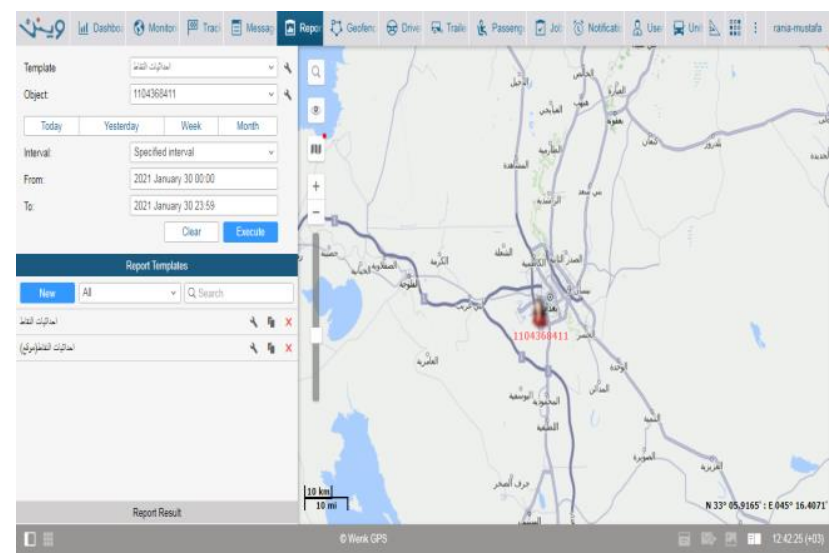

Figure 2. WENK GPS interface
For each route, data on travel time is retrieved from WENK GPS at 10-second intervals. Every 5 minutes, the trip time for each section is computed using station data. The statistics regarding travel time is calculated for a single day. Weekends and public holidays are excluded from the data collection and analysis. Tables 1 and 2 display the data sheet.

\section{Estimation of Travel Time, Speed, and Stops}

Average speeds, maximum stops, and average travel times were gathered from 45 routes in 45 days $(\mathrm{N}=45)$ to calculate the route's travel time. The data from the WENK GPS device was saved as a text file. The data has to be pre-processed. First, data normalization was performed using the dataset's lowest and maximum values. Second, the average speed for the most congested working day was computed using the normal distribution, commonly known as the bell curve. A mathematical formula is used to define the normal distribution. This method may be used to calculate the proportion of values in any interval (a, b) [11].

$\operatorname{Pr}(a<x<b)=\int_{a}^{b} \frac{1}{\sqrt{2 \pi s}} e^{1 \frac{1}{2}\left(\frac{x-m}{s}\right)^{2}} d x$ 
Table 1. Travel survey data for private cars in all weekdays for Route 1

\begin{tabular}{ccccccc}
\hline Weekday & $\begin{array}{c}\text { AM Average } \\
\text { Speed }(\mathbf{k m})\end{array}$ & $\begin{array}{c}\text { PM Average } \\
\text { Speed }(\mathbf{k m})\end{array}$ & $\begin{array}{c}\text { AM Average } \\
\text { Travel time } \\
(\mathbf{m m}: \mathbf{s s})\end{array}$ & $\begin{array}{c}\text { PM Average Travel } \\
\text { time (hh:mm:ss) }\end{array}$ & $\begin{array}{c}\text { AM } \\
\text { Average } \\
\text { Stops }\end{array}$ & $\begin{array}{c}\text { PM } \\
\text { Average } \\
\text { Stops }\end{array}$ \\
\hline Sunday & 18 & 16 & $46: 25$ & $56: 23$ & 19 & 12 \\
Monday & 12 & 8 & $59: 06$ & $1: 04: 51$ & 21 & 17 \\
Tuesday & 33 & 13 & $34: 50$ & $1: 11: 02$ & 7 & 26 \\
Wednesday & 29 & 20 & $58: 20$ & $1: 01: 14$ & 5 & 20 \\
Thursday & 33 & 15 & $41: 15$ & $1: 08: 37$ & 8 & 18 \\
Friday & 71 & 76 & $33: 29$ & $25: 43$ & 4 & 3 \\
\hline
\end{tabular}

Table 2. Travel survey data for private cars in all weekdays for Route 2

\begin{tabular}{ccccccc}
\hline Weekday & $\begin{array}{c}\text { AM Average } \\
\text { Speed }(\mathbf{k m})\end{array}$ & $\begin{array}{c}\text { PM Average } \\
\text { Speed }(\mathbf{k m})\end{array}$ & $\begin{array}{c}\text { AM Average } \\
\text { Travel time } \\
(\mathbf{m m}: \mathbf{s s})\end{array}$ & $\begin{array}{c}\text { PM Average Travel } \\
\text { time (hh:mm:ss) }\end{array}$ & $\begin{array}{c}\text { AM } \\
\text { Average } \\
\text { Stops }\end{array}$ & $\begin{array}{c}\text { PM } \\
\text { Average } \\
\text { Stops }\end{array}$ \\
\hline Sunday & 11 & 10 & $33: 15$ & $26: 17$ & 13 & 18 \\
Monday & 12 & 8 & $24: 40$ & $37: 24$ & 24 & 17 \\
Tuesday & 14 & 7 & $18: 59$ & $31: 49$ & 9 & 15 \\
Wednesday & 11 & 9 & $18: 34$ & $29: 22$ & 5 & 19 \\
Thursday & 24 & 8 & $18: 37$ & $19: 30$ & 3 & 13 \\
Friday & 62 & 72 & $17: 39$ & $17: 10$ & 4 & 3 \\
\hline
\end{tabular}

Only two parameters, $\mathrm{m}$ and $\mathrm{s}$, describe the equation entirely. The remaining characters in the formula indicate the determined interval endpoints, a and $\mathrm{b}$, as well as known mathematical constants $\pi$ and e. The average (also known as the mean) and standard deviation (SD) of the distribution are the two parameters $m$ and $\mathrm{s}$, respectively. The distribution is symmetric, with the average near the center, and the majority of values (about 95 percent) are within two standard deviations of the average. Because the distribution is characterized by only two parameters, if a dataset is approximated by a normal distribution, all of the information required to describe the distribution may be contained in just two numbers: the average and standard deviation [12]. Finally, in vector space, average speeds, maximum stops, and average trip duration were displayed. This was done to determine if the data could be separated linearly or nonlinearly, as well as which distance approach to use in this investigation.

\section{Results and Discussions}

\subsection{Analysis of Travel Time and Delays}

In data collection, more than 30 runs were performed for each route as specified by the route name. The analysis of travel time, speed, and stops is necessary for evaluating accessibility and determining the accessibility performance of the Al-Bayaa -Bab Al-Mutham routes. Figures 3 to 6 show the changes in travel time and delay for each route (morning and evening peak-hour) over the course of a week. The total trip time minus the optimal travel time for each route is calculated using the posted speed limit and distance for that route. According to the obtained results (figures 3-6), route (1) from Al-Bayaa Bab Al-Mutham intersections produced significantly higher travel and delay time values than the other route for a variety of reasons, including the surrounding commercial, residential, and educational mix land use, which generated and attracted a large number of daily trips. It is also connected to the road's traffic conditions, which are regulated by a check point near the Bab Al-Mutham intersection, resulting in excessive delays of up to five minutes during 
peak hours, resulting in vehicles coming to a complete halt and going slowly.

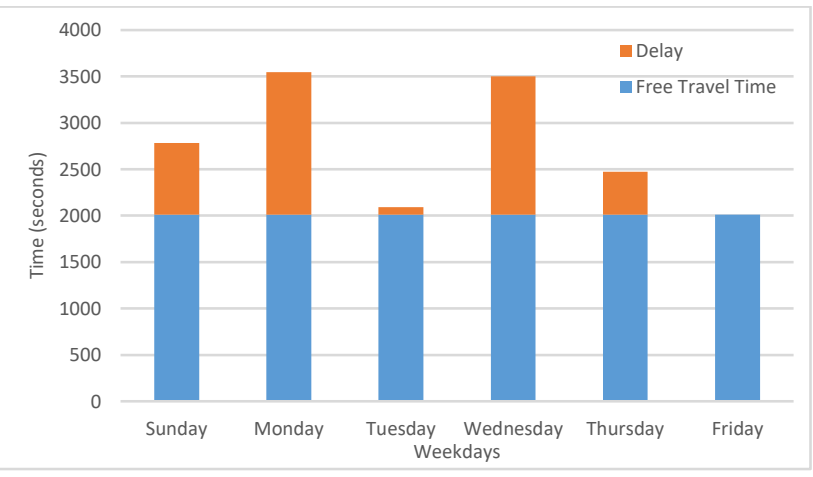

Figure 3. Total average travel time and delay variations during morning peak hour for Route 1

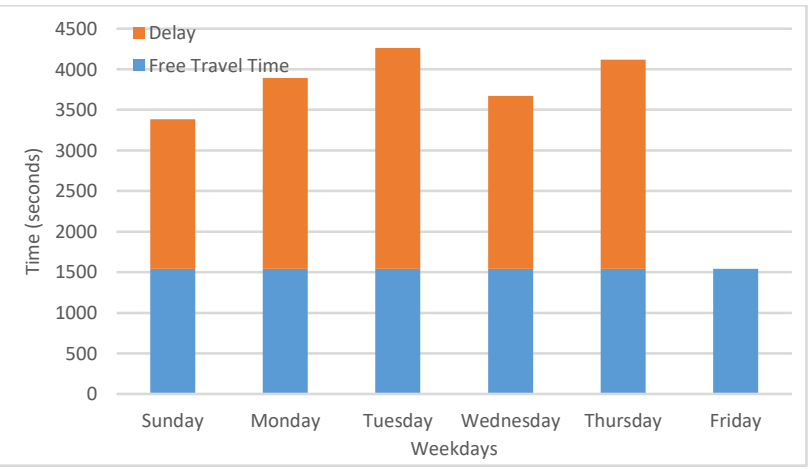

Figure 4. Total average travel time and delay variations evening during peak hour for Route 1

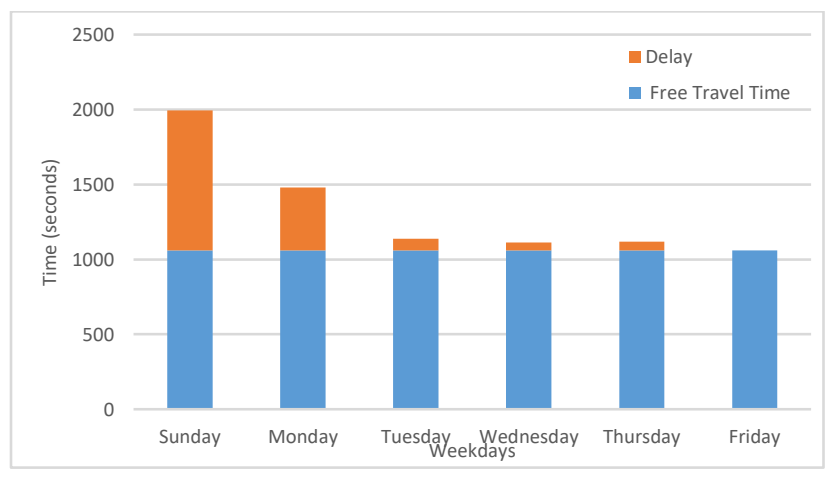

Figure 5. Total average travel time and delay variations morning during peak hour for Route 2

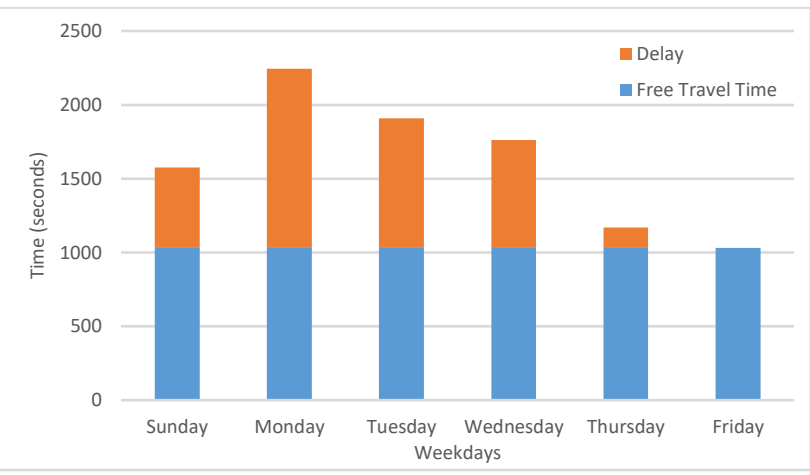

Figure 6. Total average travel time and delay variations evening during peak hour for Route 2

In Figures (3 and 6) Monday on both routes have a much higher travel time throughout the day than other typical weekdays. While in Fig. (4 and 5) Tuesday and Sunday have the higher travel time throughout the day than other typical weekdays. With maximum travel time of 71 minutes and 37 minutes for route 1 and 2, respectively. 45 minutes delay time due to condition of traffic congestion on Route (1). While, 20 minutes delay time from travel time was occurred due to condition of traffic congestion on Route (2).

\section{Analysis of Speed Variations}

Congestion of traffic conditions is a key factor in this study throughout peak hours of the day from 8:00 a.m. to 5:00 p.m. (7:00-9:00 am and 1:00 to 3:00 p.m.). These times are recommended for examining the differences in total journey time and travel delay time for each route in the chosen location. Each route has more than 30 runs, as indicated by the route name in the preceding part of data gathering. For assessing performance and getting an idea of the operating efficiency of the Al-Bayaa -Bab Al-Mutham routes, an examination of travel duration, speed, and stops is necessary. The differences in total journey time, speed, and pauses for each route are depicted in Figures 7 to 10. (morning and evening peak-hour). 


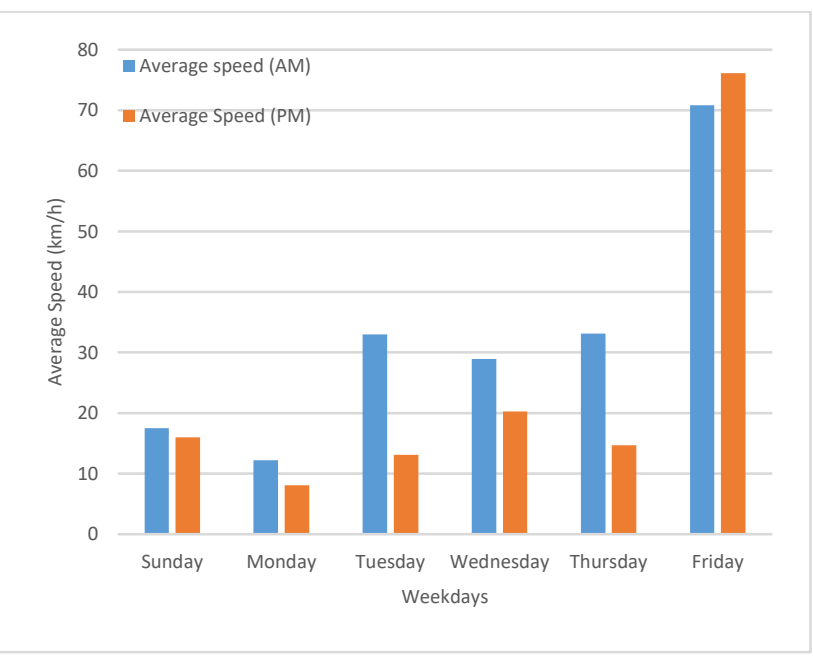

Figure 7. Total average speed variations during peak hour (AM \& PM) for Route 1

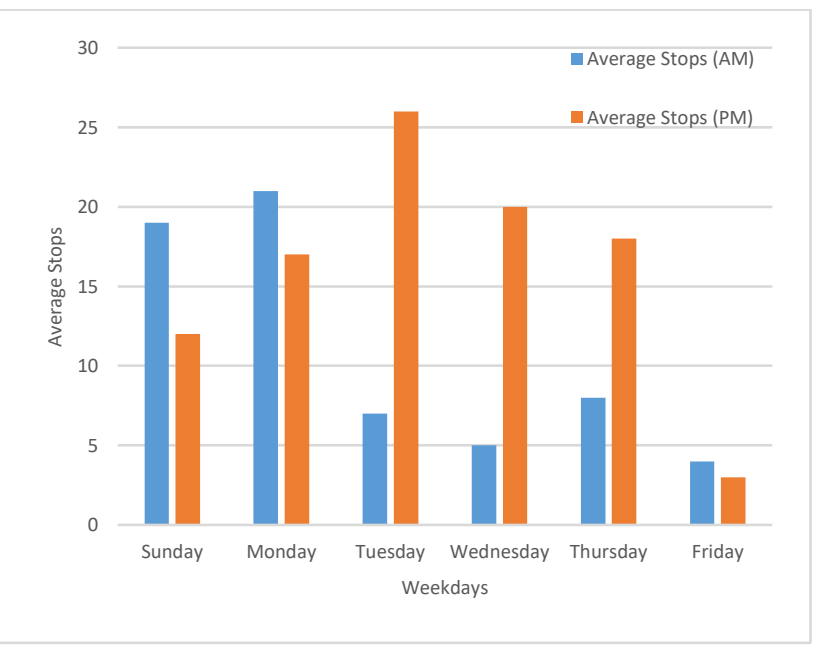

Figure 8. Total average stops variations during peak hour (AM \& PM) for Route 1

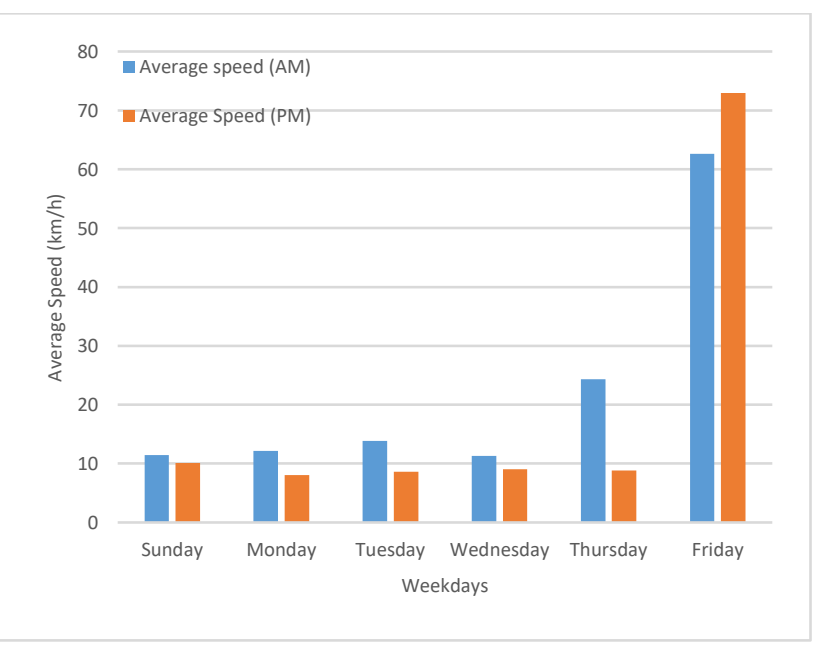

Figure 9. Total average speed variations during peak hour (AM \& PM) for Route 2

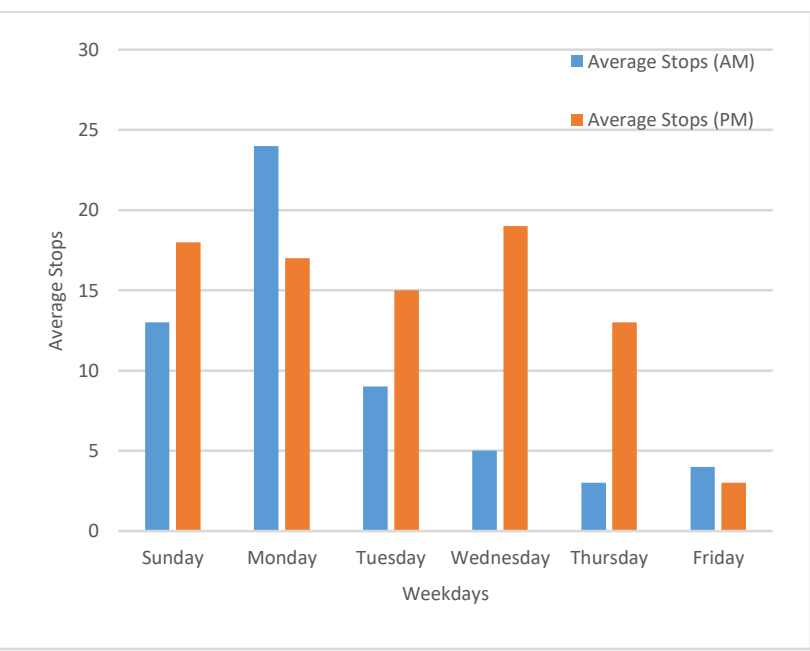

Figure 10. Total average stops variations during peak hour (AM \& PM) for Route 2

In Figures (7 and 9), the measured speeds on the Routes 1 and 2 are clustered below the local speed limit of $70 \mathrm{kmph}$ with most speeds occurring in the $25 \mathrm{kmph}$ range. While in Fig. (8 and 10) high number of stopping delay were observed on Monday and Tuesday for both routes in morning and evening peak hours. More than 20 stopping delay per trip made a significant delay in time.

\section{Estimation of Speed Distribution}

As described previously, 30 test runs with 5minute intervals were collected from field data using a GPS device to investigate the behavior of travel time variation on two routes that exhibit significant variation and a multimodal shape due to delays at unsignalized intersections and impedance caused by traffic jams on the selected routes during peak periods. A normal distribution is fitted to the field data using SPSS ver.22 statistical software. The figures (11) and (12) show histograms with normal curves for Routes (1) and (2), respectively. According to the findings of the normality test in Tables (3) and (4) for Routes (1) and (2), which indicated a significant level of $\mathrm{p}$-value greater than 0.05 . 
Table 3. Descriptive statistics of normal distribution for average speed (am) at Monday for route (1).

\begin{tabular}{ccc}
\hline Descriptive & \multicolumn{2}{c}{ Statistic Std. Error } \\
\hline Mean & 12.18 & 2.076 \\
95\% Confidence Lower Bound & 8.01 & \\
Interval for Mean Upper Bound & 16.35 & \\
5\% Trimmed Mean & 11.11 & \\
Median & 5.00 & \\
Variance & 219.748 & \\
Std. Deviation & 14.824 & \\
Minimum & 0 & \\
Maximum & 48 & \\
Range & 48 & \\
Interquartile Range & 26 & \\
Skewness & .825 & .333 \\
Kurtosis & -.762 & .656 \\
\hline
\end{tabular}

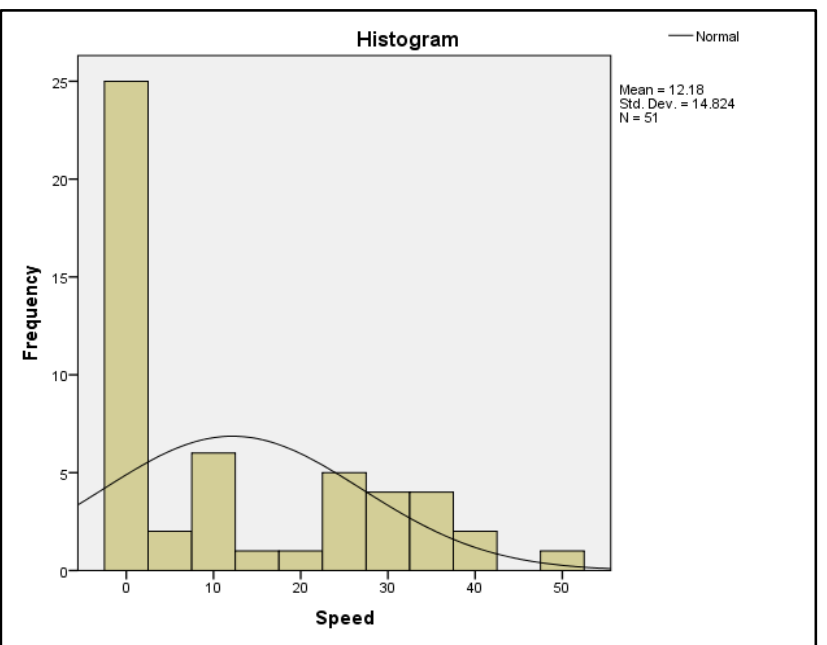

Figure 11. Normal average speed distribution (AM) on Monday (14-12-2020) for Route (1)

Table 3. Descriptive statistics of normal distribution for average speed (am) at Monday for route (1).

\begin{tabular}{cccc}
\hline Descriptive & Statistic & Std. Error \\
\hline Mean & 11.48 & 2.548 \\
& Lower & 6.24 & \\
95\% Confidence & Bound & & \\
Interval for Mean & Upper & 16.72 & \\
& Bound & & \\
5\% Trimmed Mean & 10.76 & \\
Median & 5.00 & \\
Variance & 175.336 & \\
Std. Deviation & 13.241 & \\
Minimum & 0 & \\
Maximum & 36 & \\
Range & 36 & \\
Interquartile Range & 24 & \\
Skewness & .652 & .448 \\
Kurtosis & -1.093 & .872 \\
\hline
\end{tabular}

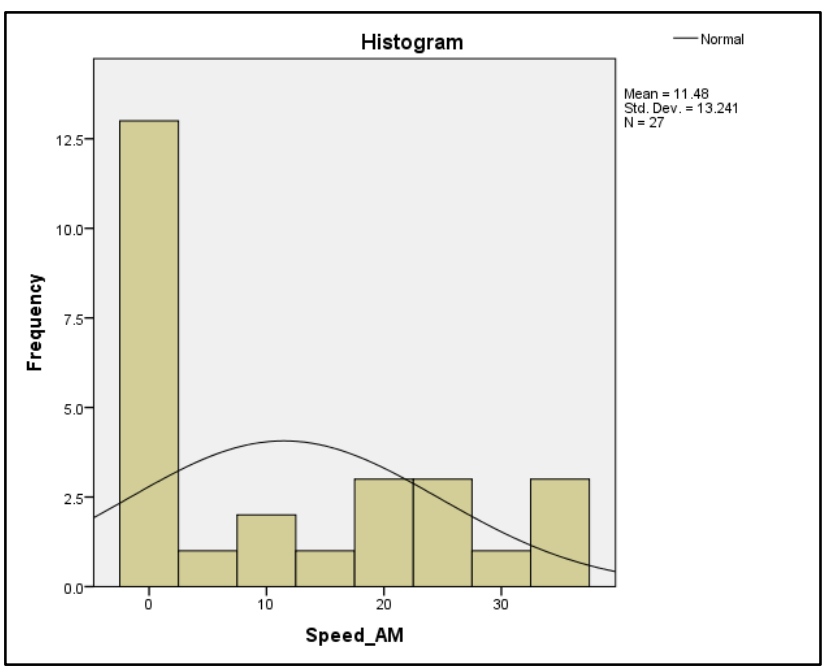

Figure 12. Normal average speed distribution (AM) on Monday (21-12-2020) for Route (2)

Calculated using the speed normal distribution table generated for speed (AM) on Monday for routes (1) and (2) and a histogram plotting speedclass intervals vs $\%$ frequency of vehicle speed, the arithmetical mean of all speeds, which reflects the average speed, has been calculated (Tables 3 and 4). Traffic on highways 1 and 2 averaged 12.18 and $11.48 \mathrm{~km} / \mathrm{h}$, with standard deviations of 14.824 and $13.241 \mathrm{~km} / \mathrm{h}$, respectively, according to the National Highway Traffic Safety Administration. It shows that vehicle speeds vary significantly when going along the route section in question.

It can be seen in figures 11 and 12 that vehicle speeds tend to cluster around the mean value and that the frequency of occurrence diminishes when the speed deviates from the mean value. This demonstrates that the great majority of cars are capable of driving at regular speeds, with just a small number of vehicles being capable of exceeding normal speeds.

\section{Conclusion}

The study presents a GPS-based travel time speed, stops, and delay survey and data analysis for vital routes in Baghdad city, Route (1) from Bayaa intersection - Bab Al-Mutham intersection (highway route) and route (2) Bayaa intersection 
- Bab Al-Mutham intersection (downtown route). It can be drawn the following points:

1. Routes 1 and 2 are clustered below the local speed limit of $70 \mathrm{kmph}$ with most speeds occurring in peak-hours are $25 \mathrm{kmph}$ in range.

2. With maximum travel time of 71 minutes and 37 minutes for route 1 and 2 respectively. 45 minutes delay time was occurred due to traffic congestion on Route (1). While, 20 minutes delay time from travel time is lost due to condition of traffic congestion on Route (2).

3. The research of traffic congestion on both routes revealed that there is a substantial variance in speed for private vehicles, which causes congestion and delays. With a standard deviation of 14.824 and 13.241, respectively, the average speed of Routes 1 and 2 is determined to be 12.18 and 11.48 $\mathrm{km} / \mathrm{h}$, with a standard deviation of 14.824 and 13.241. It implies that the speeds of the cars fluctuated substantially as they were traveling down the section of road.

4. The vast majority of vehicles traveled at normal speeds, with only a small number traveling at speeds below the average.

\section{Conflict of interest}

The authors confirm that the publication of this article causes no conflict of interest.

\section{References}

1. Al-Kaissi, Z.A. (2017). "Travel time prediction models and reliability indices for palestine urban road in baghdad city", Al-Khwarizmi Engineering Journal, V. 13, pp. 120-130.

2. Sekhar, C.R., Madhu, E., Kanagadurai, B. , and Gangopadhyay, S. (2013). "Analysis of travel time reliability of an urban corridor using micro simulation techniques",
Current Science, pp. 319-329.

3. Systematics, C. (2005). "Traffic congestion and reliability: trends and advanced strategies for congestion mitigation" United States. Federal Highway Administration.

4. Rao, A.M. and Rao, K.R. (2012). "Measuring urban traffic congestion-a review", International Journal for Traffic \& Transport Engineering, V. 2, No. 4.

5. Benekohal, R.F. (1997). "Traffic congestion and traffic safety in the 21 st century: challenges, innovations, and opportunities", in: ASCE

6. Taylor, B.D. (2002). "Rethinking traffic congestion", Access Magazine. V. 1 p.p: 816.

7. Hunter, M.P., Kook Wu, S., and Kyoung Kim, H. (2006). "Practical procedure to collect arterial travel time data using GPSinstrumented test vehicles" Transportation research record. p.p: 160-168.

8. Mazloumi, E., Currie, G., and Rose, G. (2010). "Using GPS data to gain insight into public transport travel time variability", Journal of Transportation Engineering, V. 136, p.p: 623-631.

9. Hossain, M.T., and Hasan, M.K. (2019). "Speed analysis approach to evaluate traffic congestion in pabna town" Planning. V. 4, p.p: 39-47.

10. Turner, S.M., Eisele, W.L., Benz, R.J., and Holdener, D.J. (1998). "Travel time data collection handbook" United States. Federal Highway Administration.

11. Jensen, A.F., and Larsen, T.V. (2014). "Travel-time estimation in road networks using GPS data", White Paper. V. 8.

12. Jenelius, E., and Koutsopoulos, H.N. (2013). "Travel time estimation for urban road networks using low frequency probe vehicle data", Transportation Research Part B: Methodological. V.53 p.p: 64-81. 